Short Paper

\title{
Two Spawning Seasons of the Japanese Sardine in Hiuchi-nada, the Central Seto Inland Sea
}

\author{
Jun Shoji, ${ }^{* 1}$ Tsutomu Maehara, ${ }^{* 2, \dagger}$ and Masaru Tanaka*1 \\ ${ }^{*}$ Division of Applied Biosciences, Graduate School of Agriculture, Kyoto University, \\ Kitashirakawa, Kyoto 606-8502, Japan \\ ${ }^{* 2}$ Toyo Branch, Ehime Prefectural Chuyo Fisheries Experimental Station, Kawarazu, Toyo, \\ Ehime 799-1303, Japan
}

(Received July 22, 1998)

Key words: Japanese sardine, larvae, hatch date, spawning season, Hiuchi-nada, Seto Inland Sea

The vast increase in the Japanese sardine Sardinops melanostictus population around Japan, especially along the Pacific coast, since the 1970s brought an extension of the spawning area into the Seto Inland Sea where the sardine biomass had been small." It has been supposed that the increase in abundance of Japanese sardine caused changes in prey-predator relationships and the structure of the pelagic fish community in the Seto Inland Sea. ${ }^{2}$

Since the end of the 1980s the sardine population around Japan began to drastically decline owing to high mortalities during the early life stages for four consecutive years. ${ }^{3)}$ However, in Hiuchi-nada of the central Seto Inland Sea, annual catch of the sardine has increased in recent years and reached $1,978 \mathrm{t}$ in $1996{ }^{* 1}$ Sardine larvae have been commonly by-caught by "Patchi-ami", a boat seine fishery which mainly exploits Japanese anchovy Engraulis japonica larvae and juveniles, in some areas of the Seto Inland Sea, Hiuchi-nada, ${ }^{4)}$ Hiroshima Bay, ${ }^{\text {,) }}$ and Akinada, ${ }^{* 2}$ in the $1990 \mathrm{~s}$. The sardine has become an important resource for gill net and seine fisheries particularly in Hiuchi-nada, ${ }^{* 1}$ while little is known about the reproductive biology. Previous reports ${ }^{4,6}$ were restricted to larval or juvenile sardine occurring in spring to summer because of the limited season for the boat seine fishery. We conducted year-round sampling to investigate occurrence of the sardine larvae in Hiuchi-nada and to examine the hatch date using otolith microstructures.

Larvae lured by a $300 \mathrm{~W}$ lamp at night were sampled using two types of scoop nets $(0.2$ and $2 \mathrm{~mm}$ mesh) at Kawarazu fishing port, Ehime Prefecture, facing southern Hiuchi-nada, the central Seto Inland Sea. We sampled for one to three hours after sunset, once to three times a month from March 1996 to March 1997. Collected fishes were fixed in 10\% seawater formalin and preserved in $90 \%$ ethanol within 24 hours. Sardine larvae were sorted and measured in standard lengths (SL mm). Right sagittal otolith was extracted from each fish under a dissecting microscope and counted in number of daily growth incre- ments under a compound microscope. Sea surface temperature was measured at each sampling.

A total of 209 sardine larvae ranging from $8.3-30.1 \mathrm{~mm}$ SL were collected. Occurrence of the larvae was separated into two periods: from May to June and December to February (Table 1, Fig. 1). Hatch dates of the sardine larvae were back-calculated based on the timing of the first daily ring deposition (three days after hatching at $18^{\circ} \mathrm{C}$ ) by Hayashi et al. ${ }^{\text {T }}$ The timing which corresponds to the yolk exhaustion and first feeding stage varies one or two days depending on ambient temperature, ${ }^{7,8)}$

Hatch date of the sardine larvae ranged from late April to early June and from middle October to middle January (Fig. 2). The larvae smaller than $10 \mathrm{~mm}$ SL are presumed to have hatched from early May to early June and from late November to early January. Because of small swim. ming capability, these smaller larvae seem to be spawned and hatched in Hiuchi-nada. This suggests that there are two spawning seasons in Hiuchi-nada, from May to June and from November to January, which correspond to warming and cooling seasons, respectively. The larger larvae ( $\geqq 10 \mathrm{~mm} \mathrm{SL}$ ) might have originated in Hiuchi-nada or adjacent waters.

The Japanese sardine has one major spawning season concentrated in February to April in the Pacific waters of

Table 1. Number and size range (mm SL) of Japanese sardine larvae collected by light-trap sampling in Hiuchi-nada, the central Seto Inland Sea, from March 1996 to March 1997

\begin{tabular}{rlc}
\hline Sampling date & $\mathrm{N}$ & SL range (mm) \\
\hline 1996.5 .23 & 11 & $8.3-11.4$ \\
6.11 & 49 & $8.3-27.3$ \\
12.10 & 10 & $9.1-25.1$ \\
12.21 & 58 & $8.6-29.1$ \\
1997.1 .12 & 20 & $8.5-26.8$ \\
1.20 & 14 & $9.5-30.1$ \\
2.23 & 47 & $22.3-29.7$ \\
\hline
\end{tabular}

\footnotetext{
${ }^{\dagger}$ Present Address: Agricultural Administration and Fisheries Division, Uwajima Regional Office, Ehime Prefecture, Tenjin, Uwajima, Ehime 798-0036, Japan.

$*_{1}$ Chugoku-Shikoku Regional Agricultural Administration Office: Trends of fisheries in the Seto Inland Sea, Chugoku-Shikoku Regional Agricultural Administration Office, Okayama, 1998, pp. 98 (in Japanese).

${ }^{*}$ H. Imose, K. Hatta, H. Hashimoto, K. Gushima, and T. Shibuno: Abst. Metg. Japan. Soc. Fisheries Sci., April 1996, p. 126 (in Japanese).
} 


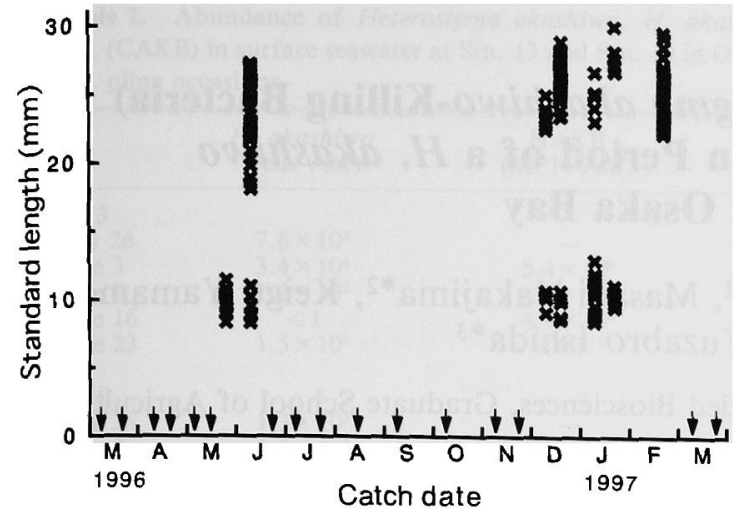

Fig. 1. Standard lengths and collection dates of 209 Japanese sardine larvae collected by light-trap sampling in Hiuchi-nada, the central Seto Inland Sea, from March 1996 to March 1997.

Arrow indicates sampling date when sardine larvae were not collected.

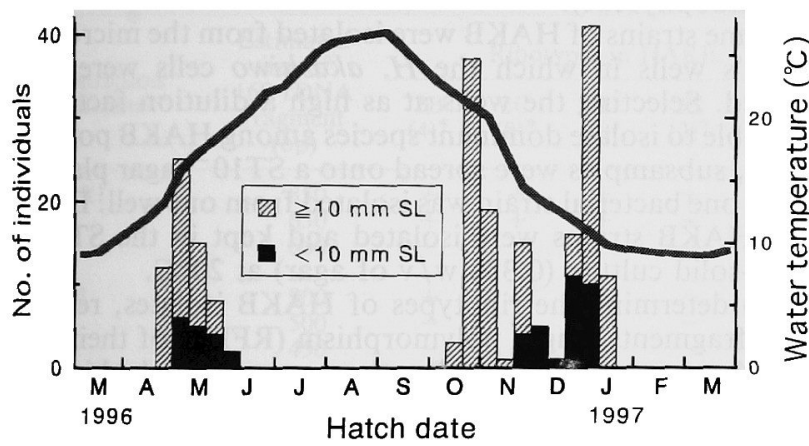

Fig. 2. Hatch date distribution of 209 Japanese sardine larvae collected by light-trap sampling in Hiuchi-nada, the central Seto Inland Sea, from March 1996 to March 1997 and water temperature (line).

Hatch dates were grouped into early, middle, and late periods of each month.

Japan,") while some of other Sardinops species, the Chilean sardine $S$. sagax and the South African Sardine $S$. ocellatus, have two separate spawning seasons. ${ }^{10-12)}$ In
Hiuchi-nada, the occurrence of the Japanese sardine larvae in autumn to winter was demonstrated in the present study in addition to that in spring to summer which had been reported., ${ }^{4,6}$ The sudden increase in autumn abundance of the sardine larvae in the late 1980s, which was observed in Sagami Bay, Pacific coast of central Japan, is considered to be associated with the biomass decline of the sardine. ${ }^{13)}$ This study was preliminarily designed to collect sardine larvae in a restricted area in Hiuchi-nada. Quantitative survey on occurrence of eggs and larvae is needed for further discussion on recent changes in reproductive traits of the sardine population in the Seto Inland Sea.

We wish to express our thanks to Mr. K. Ito, Mr. K. Shiota, Mr. T. Tanigawa, and the members of Toyo Branch, Ehime Prefectural Chuyo Fisheries Experimental Station, and to Mr. Y. Maki, Ehime Prefecture Kawarazu Fisherman's Association, for their kind help in sampling. Thanks are due to Mr. A. Watanabe, Imabari Regional Office, Ehime Prefecture and Dr. H. Hashimoto, Hiroshima Univ., for their helpful advice.

\section{References}

1) K. Kondo: Bull. Tokai Reg. Fish. Res. Lab., 124, 1-33 (1988) (in Japanese).

2) H. Hashimoto, T. Shibuno, S. Ishikawa, and K. Gushima: Scientia Marina, 59, 499-506 (1995).

3) Y. Watanabe, H. Zenitani, and R. Kimura: Can. J. Fish. Aquat. Sci., 52, 1609-1616 (1995).

4) A. Watanabe, K. Shiota, and Y. Nishiyama: Fish. Biol. Oceanogr. in the south-western waters of Japan, 11, 59-64 (1995) (in Japanese).

5) S. Ishikawa, H. Hashimoto, and K. Gushima: Fisheries Sci., 61, 523-524 (1995).

6) H. Hashimoto, S. Okajima, and S. Kakuta: J. Fac. Appl. Biol. Sci. Hiroshima Univ., 28, 79-92 (1989) (in Japanese).

7) A. Hayashi, Y. Yamashita, K. Kawaguchi, and T. Ishii: Nippon Suisan Gakkaishi, 55, 997-1000 (1989).

8) Z. Nakai: Bull. Tokai Reg. Fish. Res. Lab., 9, 109-150 (1962).

9) K. Kuroda: Bull. Natl. Res. Inst. Fish. Sci., 3, 25-278 (1991) (in Japanese).

10) D. Lluch-Belda, D. B. Lluch-Cota, S. Hernández-Vázquez, and C. A. Salinas-Zavala: S. Afr. J. Mar. Sci., 12, 147-155 (1992).

11) F. Le Clus: $S$. Afr. J. Mar. Sci., 7, 243-254 (1988).

12) F. Le Clus: S. Afr. J. Mar. Sci., 12, 123-134 (1992).

13) T. Kudo: Bull. Kanagawa Pref. Fish. Exp. Sta., 12, 73-82 (1991) (in Japanese). 